\title{
12(S)-HETE induces lymph endothelial cell retraction in vitro by upregulation of SOX18
}

\author{
ADRYAN FRISTIOHADY ${ }^{1,2}$, DANIELA MILOVANOVIC $^{3}$, SIGURD KRIEGER $^{3}$, NICOLE HUTTARY $^{3}$, \\ CHI HUU NGUYEN ${ }^{3,4}$, JOSE BASILIO ${ }^{5}$, WALTER JÄGER ${ }^{1}$, RAINER DE MARTIN $^{5}$ and GEORG KRUPITZA ${ }^{3}$ \\ ${ }^{1}$ Department of Clinical Pharmacy and Diagnostics, Faculty of Life Sciences, University of Vienna, \\ A-1090 Vienna, Austria; ${ }^{2}$ Faculty of Pharmacy, Halu Oleo University, Kendari 93232, Indonesia; \\ Departments of ${ }^{3}$ Pathology and ${ }^{4}$ Medicine I, Medical University of Vienna; ${ }^{5}$ Department of Vascular Biology \\ and Thrombosis Research, Centre of Biomolecular Medicine and Pharmacology, \\ Medical University of Vienna, A-1090 Vienna, Austria
}

Received January 5, 2018; Accepted March 6, 2018

DOI: 10.3892/ijo.2018.4378

\begin{abstract}
Metastasising breast cancer cells communicate with adjacent lymph endothelia, intravasate and disseminate through lymphatic routes, colonise lymph nodes and finally metastasize to distant organs. Thus, understanding and blocking intravasation may attenuate the metastatic cascade at an early step. As a trigger factor, which causes the retraction of lymph endothelial cells (LECs) and opens entry ports for tumour cell intravasation, MDA-MB231 breast cancer cells secrete the pro-metastatic arachidonic acid metabolite, 12S-hydroxy-5Z,8Z,10E,14Z-eicosatetraenoic acid [12(S)-HETE]. In the current study, treatment of LECs with 12(S)-HETE upregulated the expression of the transcription factors SRY-related HMG-box 18 (SOX18) and prospero homeobox protein 1 (PROX1), which determine endothelial development. Thus, whether they have a role in LEC retraction was determined using a validated intravasation assay, small
\end{abstract}

Correspondence to: Dr Georg Krupitza, Department of Pathology, Medical University of Vienna, 18-20 Waehringer Guertel, A-1090 Vienna, Austria

E-mail: georg.krupitza@meduniwien.ac.at

Abbreviations: 12(S)-HETE, 12S-hydroxy-5Z,8Z,10E,14Zeicosatetraenoic acid, 'S' stereoisomer; 12-HETER, 12(S)-HETE receptor; BLT2, leukotriene B4 receptor 2; CCID, circular chemo repellent induced defect; EC, endothelial cell; HUVEC, human umbilical vein endothelial cell; ICAM-1, intercellular adhesion molecule 1; I $\mathrm{KB} \alpha$, inhibitor of nuclear factor $\kappa$-light-chain-enhancer of activated B cells; LEC, lymph endothelial cell; miR, microRNA; NFKB1, nuclear factor of $\kappa$ light polypeptide gene enhancer in $\mathrm{B}$ cells 1 ; NF- $\kappa \mathrm{B}$, nuclear factor $\kappa$-light-chain-enhancer of activated B cells; PROX1, prospero homeobox protein 1; RELA, v-Rel avian reticuloendotheliosis viral oncogene homolog A; siRNA, small interfering RNA; SOX18, SRY-related HMG-box 18

Key words: breast cancer, endothelial retraction, SRY-related HMG-box 18, prospero homeobox protein 1, nuclear factor $\kappa$-lightchain-enhancer of activated $B$ cells interfering RNA mediated knockdown of gene expression, and mRNA and protein expression analyses. Specific inhibition of SOX18 or PROX1 significantly attenuated in vitro intravasation of MDA-MB231 spheroids through the LEC barrier and 12(S)-HETE-triggered signals were transduced by the high and low affinity receptors, 12(S)-HETE receptor and leukotriene $\mathrm{B} 4$ receptor 2. In addition, the current findings indicate that there is crosstalk between SOX18 and nuclear factor $\kappa$-lightchain-enhancer of activated B cells, which was demonstrated to contribute to MDA-MB231/lymph endothelial intravasation. The present data demonstrate that the endothelial-specific and lymph endothelial-specific transcription factors SOX18 and PROX1 contribute to LEC retraction.

\section{Introduction}

Cancer cells undergo several obligatory biochemical/molecular changes to colonise distant organs (1). In this process, tumour intravasation is an early step when cancer cells enter the vasculature (2). Breast cancer cells predominantly spread through lymphatics (3), rather than blood vessels, and lymph node metastasis in patients with breast cancer is an intermediate, yet rate-limiting step, preceding distant organ metastasis (4). Thus, the 'lymph node status' is a prognostic marker (5) and blocking lymph node metastasis is expected to positively correlate with survival. As endothelial vessel formation is crucial for tumour dissemination, the inhibition of endothelial cell growth, cell assembly and disruption of vascular integrity is a strategy to prevent tumour spreading.

SRY-related HMG-box 7 (SOX7), together with SOX18, and a limited number of other transcription factors provoke endothelial cell differentiation from mouse embryonal stem cells (6). SOX18 directly regulates (among other target genes) the transcription of prospero homeobox protein 1 (PROX1), which itself determines the differentiation from blood vessels to lymphatic vessels during embryonic development (7-11). Furthermore, as SOX18 is overexpressed in various cancer entities (12-18), this additionally renders SOX18 a candidate target to block vascularisation and metastasis. Thus, a screening approach was undertaken to identify small molecules 
that inhibit SOX18. In an extract of the marine brown algae Caulocystis cephalornithos, lead structures were discovered from which a derivative compound, sm4, was developed (19). In a breast cancer mouse model, sm4 reduced the density of blood vessels within the tumour, tumour-associated lymphatic vessels and metastatic spread (20). Conceivably, these results may lead to a first clinical trial. However, pharmacological inhibition of SOX 18 by sm 4 is not entirely specific, as the interaction of other SOX family members to their DNA promotor sites is also blocked (19). Thus, the particular contribution of SOX18, as well as mechanistic insight into its mode of action requires further investigation. To this end, we investigated the role of SOX18 and its transcriptional target, PROX1, during tumour intravasation by specifically inhibiting them with small interfering RNAs (siRNAs). A mechanism that breast cancer cells use to traverse the lymph endothelial wall is by secretion of $12 \mathrm{~S}$-hydroxy-5Z,8Z,10E,14Z-eicosatetraenoic acid [12(S)-HETE] (4), which causes endothelial cell retraction (21-23). Thus, gaps emerge in the lymph endothelial barrier [termed circular chemorepellent-induced defects (CCIDs)] through which cancer emboli can transmigrate. The results of the current study demonstrated that 12(S)-HETE strongly induced the expression of SOX18 and PROX1, and their inhibition attenuated CCID formation. Thus, the 12(S)-HETEtriggered signal transduction pathway, in addition to recently established cross-talk between SOX18 and nuclear factor $\kappa$-light-chain-enhancer of activated B cells $(\mathrm{NF}-\kappa \mathrm{B})(24,25)$, which also contributes to breast cancer cell intravasation (26-28), were examined.

\section{Material and methods}

Antibodies and reagents. Rabbit polyclonal anti-leukotriene B4 receptor 2 (BLT2; cat. no. L7042) and mouse monoclonal anti- $\beta$-actin antibody (clone AC-15; cat. no. A3854) were purchased from Sigma-Aldrich (Munich, Germany), rabbit monoclonal anti- PROX1 (clone EPR19273; cat. no. Ab119359), rabbit polyclonal anti-SOX18 (cat. no. Ab23342) and mouse monoclonal anti-intercellular adhesion molecule 1 antibody (ICAM-1; clone MEM111; cat. no. Ab2213) from Abcam (Cambridge, UK), mouse monoclonal anti-v-Rel avian reticuloendotheliosis viral oncogene homolog A (RELA/p65; clone L8F6; cat. no. 4767) from Cell Signaling Technology, Inc. (Danvers, MA, USA), polyclonal rabbit anti-nuclear factor of $\kappa$-light polypeptide gene enhancer in B cells 1 (NFKB1/p50; cat. no. SC8414) was bought from Santa Cruz Biotechnology, Inc. (Dallas, TX, USA), polyclonal rabbit anti-12(S)-HETE receptor (12-HETER; cat. no. CAYM14083-1) antibody was from Cayman Chemical Company (Ann Arbor, MI, USA), polyclonal rabbit anti-mouse (cat. no. Z0420) and polyclonal swine anti-rabbit IgGs (cat. no. E0353) were from Dako (Agilent Technologies, Inc., Santa Clara, CA, USA). The antibody dilutions used in western blotting were as follows: Anti-BLT2, 1:500; anti-12-HETER, 1:300; anti-SOX18, 1:250; anti-PROX1, 1:500; anti-ICAM-1, 1:300-500; anti-RELA/p65, 1:300; anti-NFKB1/p50, 1:500; anti- $\beta$-actin, $1: 5,000$; and anti-rabbit/anti-mouse secondary antibodies 1:2,000. All antibodies were diluted in PBS containing 5\% skim-milk.

The siRNAs targeting human SOX18 (cat. no. L-019035-000005), BLT2 (cat. no. L-005654-00-0005), 12-HETER (cat. no. L-005564-00-0005), NFKB1 (cat. no. L-003520-000005 NFKB2 (cat. no. L-003918-00-0005) and PROX1 (cat. no. L-016913-005) were from Dharmacon (Lafayette, CO, USA). The siRNA targeting human RELA (cat. no. 4390824; ID s11914) and non-targeting control siRNA (SilencerR Select Negative Control no. 1 siRNA; cat. no. 4390843) were obtained from Ambion (Thermo Fisher Scientific, Inc., Waltham, MA, USA). All siRNAs were resuspended in RNAse-free water to obtain a stock concentration of $20 \mu \mathrm{M}$.

12(S)-HETE was purchased from Cayman Chemical Company. The inhibitor of nuclear factor $\kappa$-light-chainenhancer of activated B cells $(\mathrm{I} \kappa \mathrm{B} \alpha)$ phosphorylation inhibitor (E)-3-[(4-methylphenyl)sulfonyl]-2-propenenitrile (Bay11-7082) was purchased from Calbiochem (Merck KGaA, Darmstadt, Germany).

Cell culture. Human MDA-MB231 breast cancer cells were purchased from the American Type Culture Collection (Manassas, VA, USA) and cultured in MEM medium supplemented with $10 \%$ foetal calf serum (FCS), $1 \%$ penicillin/streptomycin and $1 \%$ non-essential amino acids (all from Invitrogen; Thermo Fisher Scientific, Inc.). Microvessel endothelial cells were purchased from Clonetics ${ }^{\mathrm{TM}}$ (Lonza Group, Ltd., Basel, Switzerland), immortalized by telomerase, and then human lymph endothelial cells (LECs) were isolated from this TERT-immortalised mixture of human dermal endothelial cells $(29,30)$. LECs were authenticated by analysing expression of the lymph endothelial cell markers PROX1, lymphatic vessel endothelial hyaluronic acid receptor 1 and podoplanin, and the pan-endothelial cell marker CD31 by immunofluorescence and laser scanning microscopy (data not shown). LECs were cultured in EGM2 MV (cat. no. CC-4147; Clonetics $^{\mathrm{TM}}$; Lonza Group, Ltd.). The cells were cultured at $37^{\circ} \mathrm{C}$ in a humidified atmosphere containing $5 \% \mathrm{CO}_{2}$. For CCID formation assays, LECs were stained with cytotracker green (Invitrogen; Thermo Fisher Scientific, Inc.).

CCID assay. This assay measures the size of cell-free areas (CCIDs) in the LEC monolayer, which are triggered by MDA-MB231 tumour spheroids. MDA-MB231 cells (input of $6 \times 10^{3}$ cells per spheroid) were transferred to $30 \mathrm{ml}$ MEM medium containing $0.3 \%$ methylcellulose. Cell suspensions $(150 \mu \mathrm{l})$ were transferred to each well of 96-well round bottom microtiter plates to allow spheroid formation within the subsequent $48 \mathrm{~h}$. Then, MDA-MB231 spheroids were washed in PBS and transferred to cytotracker $(1 \mathrm{mg} / \mathrm{ml}$ final concentration)-stained LEC monolayers that were seeded into 24-well plates in $2 \mathrm{ml} \mathrm{EGM} 2 \mathrm{MV}$ medium $48 \mathrm{~h}$ before and cultured to confluence. Following the staining of LECs and 30 min pre-treatment with Bay11-7082 (or with dimethyl sulfoxide for control), the MDA-MB231 spheroids were carefully transferred to the 24-well plates containing LECs. After $4 \mathrm{~h}$ of co-incubation, the CCID areas in the LEC monolayers underneath the MDA-MB231 spheroids were imaged using an Axiovert fluorescence microscope (Zeiss GmbH, Jena, Germany) to visualise cytotracker (green)-stained LECs underneath the spheroids. CCID areas were calculated with the Axiovision Re. 4.5 software (Zeiss $\mathrm{GmbH}$ ). Experiments were performed in triplicate and for each condition, the CCID sizes underneath $\geq 12$ were measured. 
Transfection of LEC monolayer. LECs were seeded in 24-well plates $(1 \mathrm{ml} /$ well $)$ and cultured in EGM2 medium. Transfections were performed when the cells were $70-80 \%$ confluent. A total of $0.75 \mu \mathrm{g}$ siRNA ( $3 \mu \mathrm{l}$ from $20 \mu \mathrm{M}$ stock) and $6 \mu \mathrm{l}$ HiPerFect Transfection Reagent (Qiagen GmbH, Hilden, Germany) were mixed in $100 \mu \mathrm{l}$ serum-free medium and incubated for $30 \mathrm{~min}$ at room temperature to allow the formation of transfection complexes. The old cell culture medium was gently removed and $500 \mu 1$ fresh EGM2 medium were added into each well. Then the transfection complexes were added drop-wise to the cells (to a final siRNA concentration of $100 \mathrm{nM}$ ) and incubated for $24 \mathrm{~h}$ at $37^{\circ} \mathrm{C}$. After $24 \mathrm{~h}$, the medium was replaced by fresh medium and cells were incubated for another $24 \mathrm{~h}$ to recover. The LECs monolayers were used for CCID assays or isolated RNA for reverse transcription-quantitative polymerase chain reaction (RT-qPCR).

$R T-q P C R$. LECs were harvested following transfection (or stimulation) and RNA was isolated using the RNeasy Mini kit 50 and QIAshredder 50 (Qiagen $\mathrm{GmbH}$ ). The final RNA concentration was measured using a NanoDrop Fluorospectrometer (Thermo Fisher Scientific, Inc.). Total RNA $(2 \mu \mathrm{g})$ was reverse transcribed to cDNA using EcoDry Premix at $42^{\circ} \mathrm{C}$ for $60 \mathrm{~min}$ according to the manufacturer's instructions (Clontech Laboratories, Inc., Mountainview, CA, USA) and the resulting cDNA was amplified using TaqMan Gene Expression Master Mix (Applied Biosystems, Vienna, Austria) and TaqMan primer pairs (Applied Biosystems; Thermo Fisher Scientific, Inc.). IDs for the primers were as follows: GAPDH (assay ID, Hs99999905_m1), RELA (p65; assay ID, Hs00153294_m1), NFKB1 (p100; assay ID, Hs00765730_m1), NFKB2 (p105; assay ID: Hs00174517_m1), ICAM-1 (assay ID, Hs00164932_m1), SOX18 (assay ID, Hs00746079_s1) and PROX1 (assay ID, Hs00896293_m1). The cycling profile for DNA amplifications was as follows: $50^{\circ} \mathrm{C}$ for $2 \mathrm{~min}\left(1\right.$ cycle); $95^{\circ} \mathrm{C}$ for $10 \mathrm{~min}(1$ cycle $) ; 95^{\circ} \mathrm{C}$ for $15 \mathrm{sec}, 60^{\circ} \mathrm{C}$ for $30 \mathrm{sec}, 72^{\circ} \mathrm{C}$ for $30 \mathrm{sec}\left(40\right.$ cycles); and $72^{\circ} \mathrm{C}$ for $10 \mathrm{~min}$ (1 cycle). The PCR products were analysed on the Chromo4 PCR System (Bio-Rad Laboratories, Hercules, CA, USA). qPCR was performed in triplicate for each cDNA template. Gene expression was normalized to GAPDH expression and calculated using the $\Delta \Delta \mathrm{Cq}$ method (31).

Western blotting. To monitor knock down of siRNA transfected cells or to follow the activation/inactivation of signalling molecules upon 12(S)-HETE stimulation, western blot analyses were performed. LECs were seeded in 6-well plates ( $2.5 \mathrm{ml} \mathrm{medium/well)} \mathrm{and} \mathrm{stimulated} \mathrm{with} \mathrm{indicated} \mathrm{concen-}$ trations of 12(S)-HETE or for indicated times. Then, cells were washed twice with ice cold PBS and lysed in buffer containing $150 \mathrm{mM} \mathrm{NaCl}, 50 \mathrm{mM}$ Tris $\mathrm{pH}$ 8.0,0.1\% Triton X-100, $1 \mathrm{mM}$ phenylmethylsulfonylfluorid and protease inhibitor cocktail and the lysate was centrifuged at $13,500 \mathrm{x}$ g at $4^{\circ} \mathrm{C}$ for $20 \mathrm{~min}$. The supernatant was stored at $-20^{\circ} \mathrm{C}$ until further analysis. Total protein $(20 \mu \mathrm{g} /$ well; determined by Pierce bicinchoninic acid protein assay; Thermo Fisher Scientific, Inc.) was separated by $10 \%$ SDS-polyacrylamide gel electrophoresis and electro-transferred onto Hybond polyvinylidene difluoride membranes (GE Healthcare, Chicago, IL, USA) at $100 \mathrm{~V}$ for $1 \mathrm{~h}$ at $4^{\circ} \mathrm{C}$. To control equal sample loading, membranes were stained with Ponceau S (Sigma-Aldrich). Following washing with PBS/Tween-20 (PBS/T; pH 7.2) or TBS/T (pH 7.6), membranes were immersed in blocking solution (5\% non-fat dry milk in TBS containing $0.1 \%$ Tween or in PBS containing $0.5 \%$ Tween-20) at room temperature for $1 \mathrm{~h}$. Membranes were washed and incubated with primary antibody (in blocking solution; dilution $1: 500-1: 1,000)$ by gently rocking at $4^{\circ} \mathrm{C}$ overnight or at room temperature for $1 \mathrm{~h}$. Subsequently, the membranes were washed with PBS/T or TBS/T and incubated with secondary antibody (peroxidase-conjugated goat anti-rabbit IgG or anti-mouse IgG; dilution, 1:2,000) at room temperature for $1 \mathrm{~h}$. Chemiluminescence was developed by ECL-Plus detection kit (GE Healthcare), and detected using a Lumi Imager F1 Workstation (Roche Diagnostics, Basel, Switzerland). Densitometry of the western blots was analysed with ImageJ software (National Institutes of Health, Bethesda, MA, USA).

Statistical analysis. For statistical analyses Excel 2013 software (Microsoft Corporation, Redmond, WA, USA) and Prism 6 software package (GraphPad Software, San Diego, CA, USA) were used. The values are expressed as the mean \pm standard error, t-test or one-way analysis of variance with Tukey's post-test and were applied to compare differences between control samples and treatment groups. $\mathrm{P}<0.05$ was considered to indicate a statistically significant difference.

\section{Results}

12(S)-HETE induces SOX18. 12(S)-HETE reduces the resilience of the lymph endothelial barrier (4) through activation of NF- $\kappa \mathrm{B}(26,27)$. Reportedly, NF- $\kappa \mathrm{B}$ cross-talks to the endothelia-specific transcription factor SOX18 in human umbilical vein endothelial cells (HUVECs) (24). This prompted investigation of the expression of SOX18 in LECs upon 12(S)-HETE treatment. Treatment with 0.5 and $1 \mu \mathrm{M}$ 12(S)-HETE significantly increased SOX18 mRNA (Fig. 1A) and protein expression, which was dependent on dose (Fig. 1B) and time (Fig. 1C).

12(S)-HETE signals to SOX18 through 12(S)-HETE receptor (12-HETER) and BLT2 and contributes to LEC barrier breaching in vitro. 12(S)-HETE increased SOX18 mRNA and protein expression, which was dependent on the high affinity receptor 12-HETER and the low affinity receptor BLT2, as siRNAs targeting 12-HETER and BLT2, inhibited 12(S)-HETE-induced SOX18 mRNA overexpression (Fig. 2A) and SOX18 protein upregulation (Fig. 2B). As 12(S)-HETE causes the retraction of LECs (4), whether SOX18 and BLT2 also contribute to this phenomenon was investigated. LEC retraction was measured in a validated in vitro co-culture assay calculating the areas of generated CCIDs in LEC monolayers underneath 12(S)-HETE-secreting MDA-MB231 cell spheroids $(4,32)$. The CCID areas that were triggered by MDA-MB213 spheroids were significantly smaller in those LEC monolayers, which were transfected with siRNAs targeting SOX18 or BLT2 (Fig. 2C and D, respectively). The efficient downregulation of SOX18 and BLT2 by siRNAs was determined by western blotting (Fig. 2E and F, respectively). Thus, the transcription factor SOX18 and the low affinity 12(S)-HETE receptor BLT2 


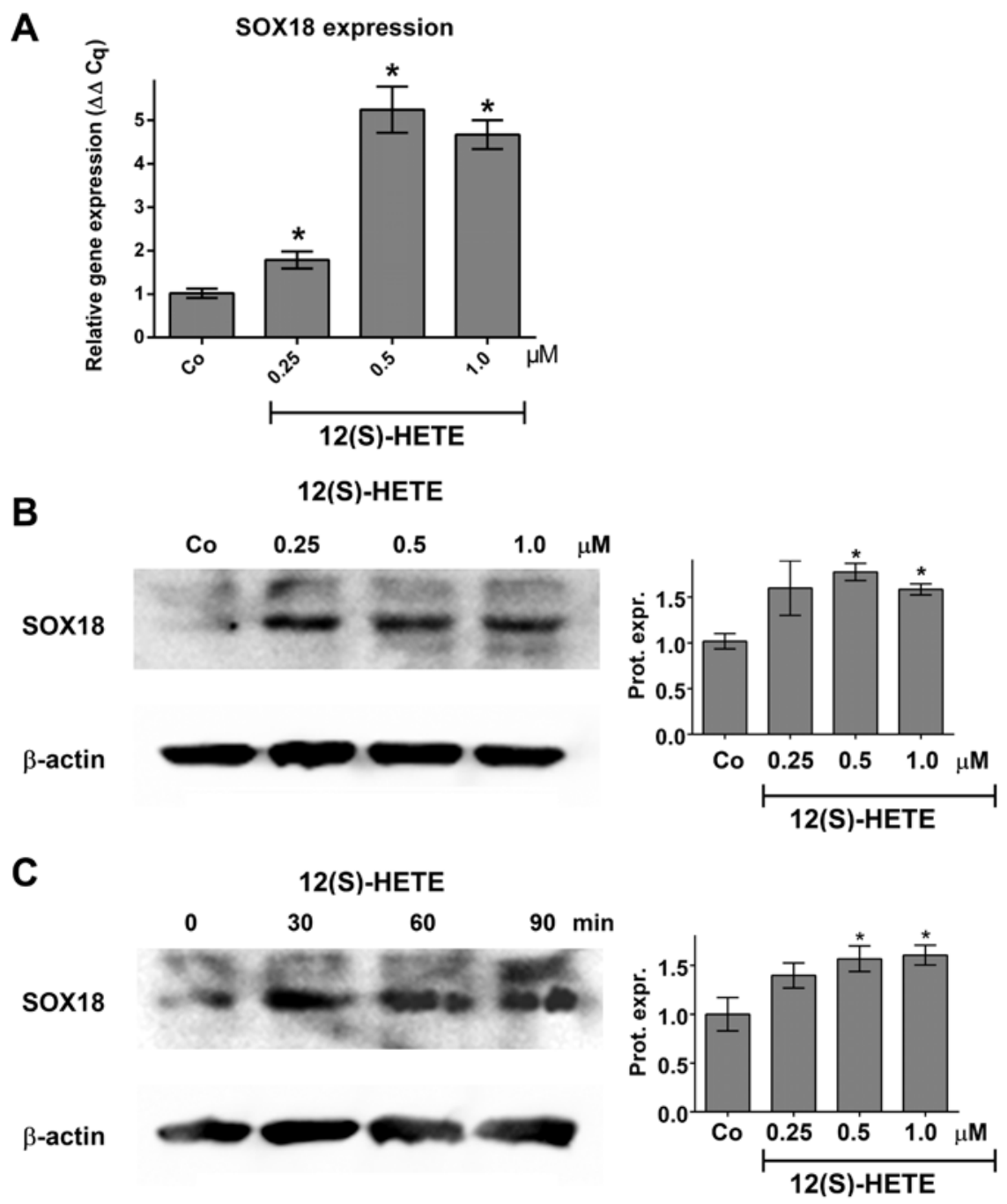

Figure 1. 12(S)-HETE induces SOX18 expression. LECs were treated with solvent (DMSO, Co) or the indicated concentrations of 12(S)-HETE (A) for $15 \mathrm{~min}$ when cells were lysed and analysed by reverse transcription-quantitative polymerase chain reaction for SOX18 mRNA expression (normalised to GAPDH mRNA), or (B) for $1 \mathrm{~h}$ when proteins were separated by SDS-PAGE and SOX18 expression analysed by western blotting using SOX18 antibody (Ponceau S-staining and $\beta$-actin expression served as loading controls). The relative protein expression was quantified by densitometry (three replicates each). (C) LECs were treated with solvent or $0.5 \mu \mathrm{M}$ 12(S)-HETE for the indicated times when cells were lysed and SOX18 protein expression was analysed. Values are presented as the mean \pm standard error. " $\mathrm{P}<0.05$ vs. Co (one-way analysis of variance with Tukey's post hoc test). LECs, lymph endothelial cells; SOX18, SRY-related HMG-box 18; 12(S)-HETE, 12S-hydroxy-5Z,8Z,10E,14Z-eicosatetraenoic acid; Co, control.

contributed to LEC retraction. The role of 12-HETER for LEC retraction was demonstrated previously, as well as the downregulation of 12-HETER by siRNA in LECs $(32,33)$.

PROX1 contributes to LEC barrier breaching. SOX18 regulates the transcription factor PROX1 (34), which in adults, is expressed in LECs and thus, is a prominent marker of lymph endothelia. Hence, the expression of PROX1 was analysed upon treatment of LECs with 12(S)-HETE. 12(S)-HETE increased PROXI mRNA expression, which was suppressed by knockdown of SOX18, 12-HETER and BLT2 (Fig. 3A). In addition, CCID formation was attenuated in PROX1 knockdown LEC monolayers (Fig. 3B). Efficient downregulation of PROX1 protein by siRNA targeting PROX1 was demonstrated by western blot analysis and densitometry (Fig. 3C). Thus, the effects produced by 12(S)-HETE and via 12-HETER/BLT2 were propagated further downstream from PROX1, which itself contributed to CCID formation by a mechanism that needs to be established.
SOX18 expression depends on RELA, NFKB1 and NFKB2. Tumour necrosis factor- $\alpha$ treatment inhibits SOX18 expression in HUVECs via NF- $\mathrm{KB} / \mathrm{RELA}$ (24) by altered binding of auxiliary factors at NF- $\mathrm{kB}$ promoter/enhancer sites (35). Thus, the interplay between NF- $\mathrm{KB}$ and SOX18 was further investigated in LECs. Treating LECs with the I $\kappa \mathrm{B} \alpha / \mathrm{NF}-\kappa \mathrm{B}$ inhibitor Bay11-7082 inhibited 12(S)-HETE-induced SOX18 protein expression. Thus, NF- $\mathrm{KB}$ activity was associated with SOX18 expression in LECs (Fig. 4A) as demonstrated previously in HUVECs. To determine causality, experiments in which RELA, NFKB1 and NFKB2 were knocked down in LECs were performed. The efficacy of the siRNAs, which downregulate RELA, NFKB1 and NFKB2 in LECs, was established previously (28). qPCR analysis demonstrated that SOX18 mRNA expression in LECs (Fig. 4B), and consequently also the expression of PROX1 mRNA (Fig. 4C), was significantly inhibited by these siRNAs. As a control, the expression of the well-established NF- $\mathrm{KB}$ target, ICAM-1, was analysed indicating that RELA, NFKB1 and NFKB2 siRNAs repressed 

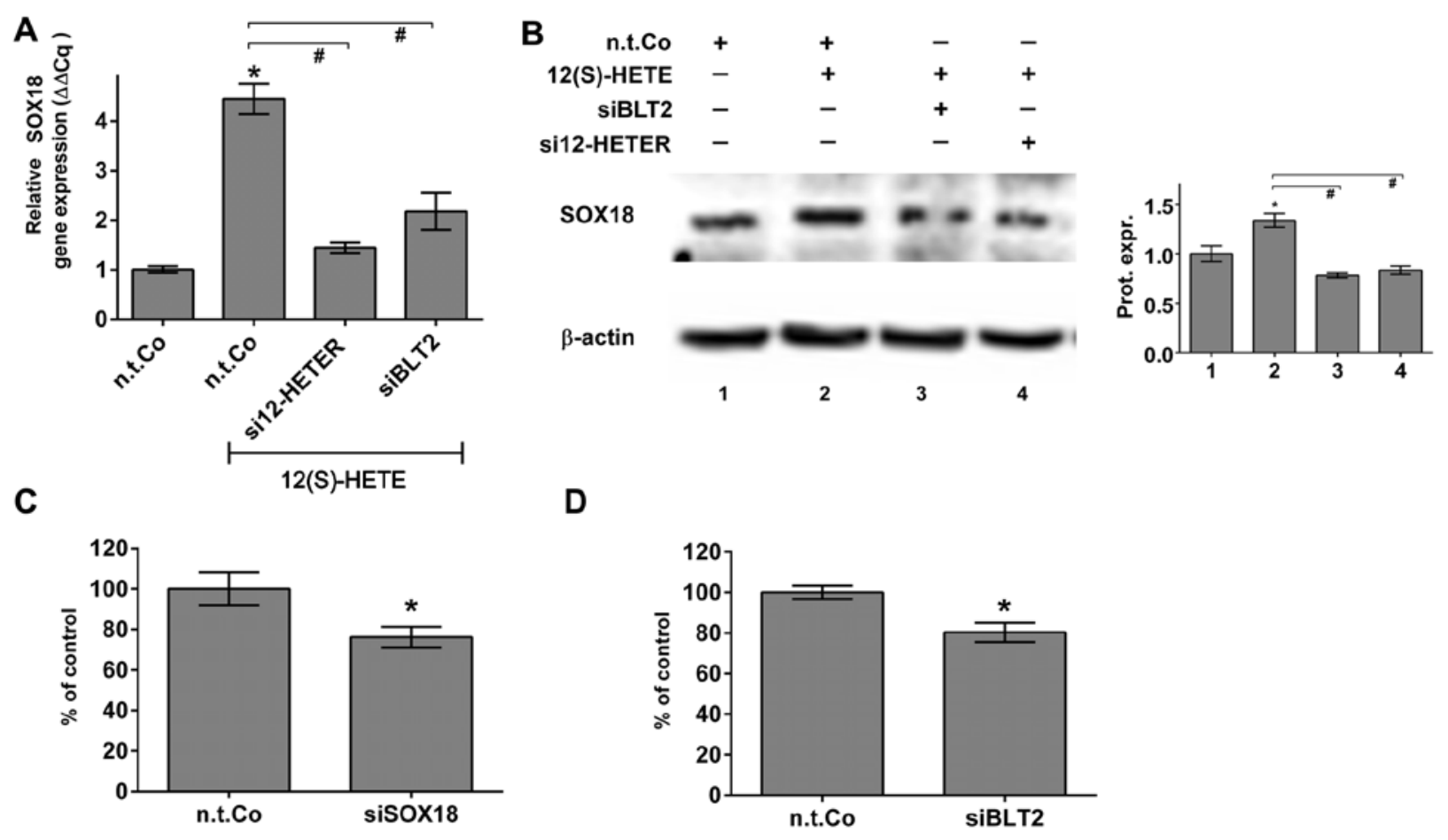

E
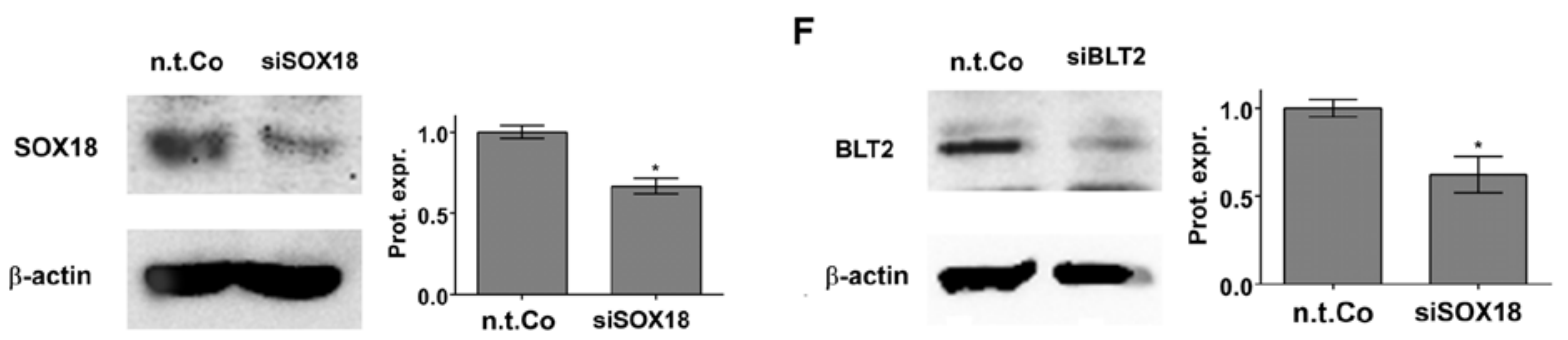

Figure 2. 12(S)-HETE signals to SOX18 through 12-HETER and BLT2 in LEC. LECs were transfected with n.t.Co or siRNA targeting BLT2 or 12-HETER. After $24 \mathrm{~h}$ cells were stimulated with solvent (DMSO; n.t.Co) or $1 \mu \mathrm{M}$ 12(S)-HETE, lysed and analysed (A) by reverse transcription-quantitative polymerase chain reaction for SOX18 mRNA expression (normalised to GAPDH mRNA), or (B) by SDS-PAGE and western blotting for SOX18 protein expression using SOX18 antibody (Ponceau S-staining and $\beta$-actin expression served as loading controls). The relative protein expression was quantified by densitometry (three replicates each). LECs were transfected with either (C) n.t.Co or siRNA targeting SOX18, or (D) siRNA targeting BLT2 and after 24 h MDA-MB231 breast cancer cell spheroids were placed on top of confluent LEC monolayers and co-incubated for $4 \mathrm{~h}$ when circular chemorepellent-induced defects formation was measured. Three independent experiments with at least 10 replicates were measured. The downregulation of (E) SOX18 protein by siSOX18 or (F) BLT2 protein by siBLT2 2 as analysed by western blotting. Values are presented as the mean \pm standard error, ${ }^{*} \mathrm{P}<0.05$ vs. n.t.Co (no 12 (S)-HETE); ${ }^{\sharp} \mathrm{P}<0.05$ vs. n.t.Co (12(S)-HETE-treatment). LECs, lymph endothelial cells; n.t.Co, non-targeting control RNA; si, small interfering RNA; SOX18, SRY-related HMG-box 18; 12(S)-HETE, 12S-hydroxy-5Z,8Z,10E,14Z-eicosatetraenoic acid; 12-HETER, 12(S)-HETE receptor; BLT2, leukotriene B4 receptor 2.

12(S)-HETE-induced ICAM-1 mRNA induction (Fig. 4D). Similar to SOX18, the upregulation of ICAM-1 mRNA and ICAM-1 protein (Fig. 4D and E, respectively) was also mediated by 12-HETER and BLT2. The data confirmed that SOX18 was downstream of NF- $\kappa \mathrm{B}$ signalling.

SOX18 regulates RELA and NFKB1 expression. Reportedly, 12(S)-HETE signals to NF- $\kappa$ B in LECs (27) and in the former experiments the cross-talk between $\mathrm{NF}-\kappa \mathrm{B}$ and SOX18 was demonstrated. Reciprocally, it was examined whether SOX18 has a role in the expression of $\mathrm{NF}-\kappa \mathrm{B}$ following stimulation of LECs with 12(S)-HETE. Analysing the mRNA profile in LECs transfected with SOX18-targeting siRNA demonstrated that SOX18 contributed to 12(S)-HETE-induced effects on RELA and NFKB1, but not on NFKB2 (Fig. 5A-C, respectively). Furthermore, the suppression of RELA and NFKB1 protein upon SOX18 knock down in LECs suggested that SOX18 has a role upstream of NF- $\kappa \mathrm{B}$ signalling, as the expression of the established NF- $\mathrm{B}$ target, ICAM-1, was also inhibited (Fig. 5D).

As SOX18 was also demonstrated to be downstream of $\mathrm{NF}-\kappa \mathrm{B}$ (in the previous experiments), a positive feed-back loop between these transcription factors may exist in LECs.

\section{Discussion}

When breast cancer cells disseminate through the lymphatic vasculature the first lymph node reached, termed the sentinel, becomes colonised (36). The emerging lymph node metastasis is drained by de novo assembled lymphatic vessels, which perforate the neoplastic tissue $(4,37,38)$. As soon as metastatic cancer cells intravasate these de novo lymphatics they are transported to the efferent lymphatic sinus and colonise downstream lymph nodes until they reach and infest distant organs (4). Reportedly, 12(S)-HETE, which is secreted by cancer cells, triggers the retraction of 

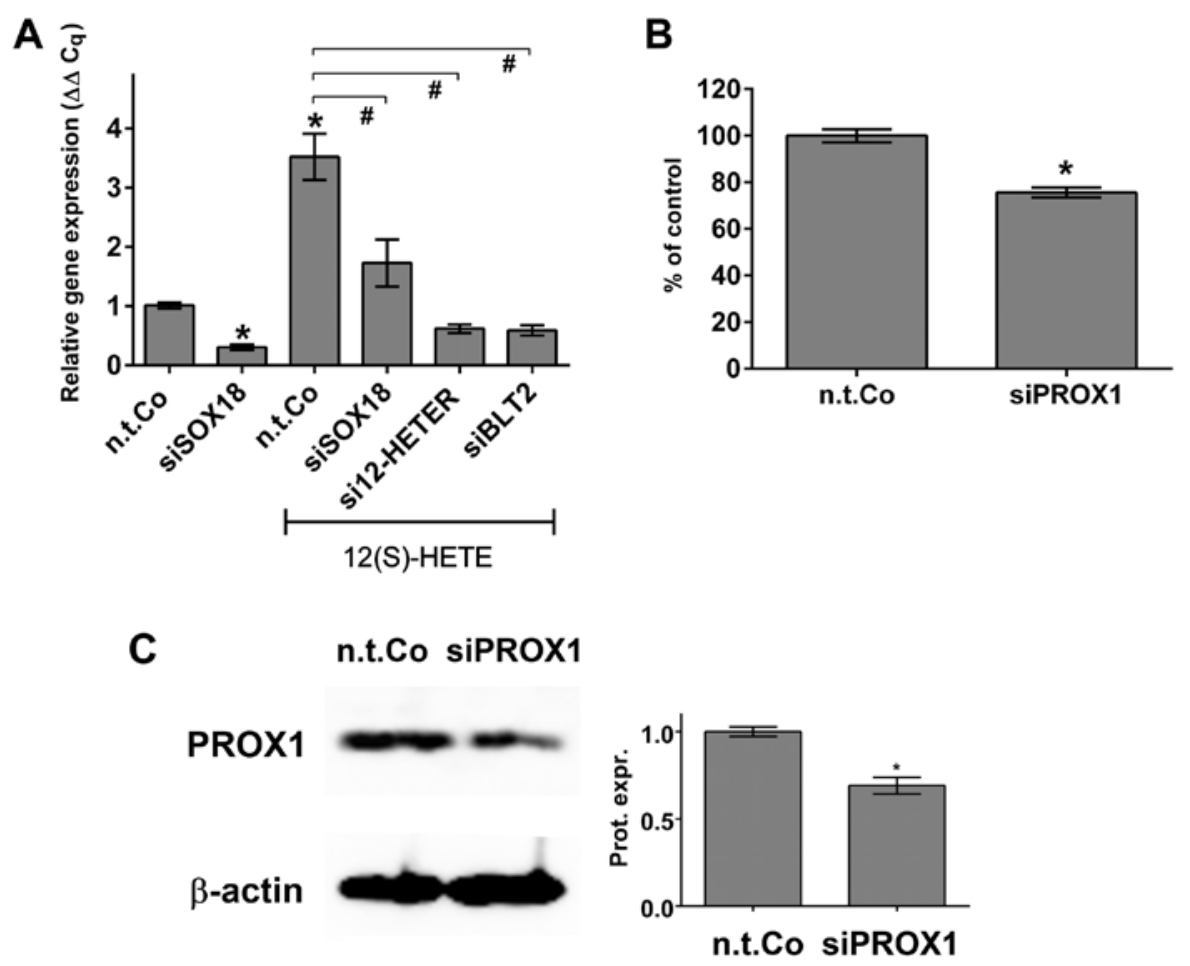

Figure 3. 12(S)-HETE induces PROX1 expression. (A) LECs were treated with solvent (DMSO, Co) or $1.0 \mu \mathrm{M}$ 12(S)-HETE for 15 min when cells were lysed and analysed by reverse transcription-quantitative polymerase chain reaction for PROX1 mRNA expression (normalised to GAPDH mRNA; quadruplicates were performed for each experimental condition). (B) LECs were transfected with either n.t.Co or siRNA targeting PROX1 and after $24 \mathrm{~h}$ MDA-MB231 breast cancer cell spheroids were placed on top of confluent LEC monolayers and co-incubated for $4 \mathrm{~h}$ when circular chemorepellent-induced defects formation was measured. Three independent experiments with at least 10 replicates were measured. (C) Downregulation of PROX1 protein by siPROX1 was analysed by SDSPAGE and western blotting using PROX1 antibody (Ponceau S-staining and $\beta$-actin expression served as loading controls). The relative protein expression was quantified by densitometry (three replicates each). Values are presented as the mean \pm standard error. ${ }^{*} \mathrm{P}<0.05$ and ${ }^{*} \mathrm{P}<0.05$ vs. n.t.Co (12(S)-HETE-treatment) LECs, lymph endothelial cells; n.t.Co, non-targeting control RNA; si, small interfering RNA; SOX18, SRY-related HMG-box 18; 12(S)-HETE, 12S-hydroxy5Z,8Z,10E,14Z-eicosatetraenoic acid; 12-HETER, 12(S)-HETE receptor; BLT2, leukotriene B4 receptor 2; PROX1, prospero homeobox protein 1.

juxtaposed LECs allowing cancer emboli to intrude through the emerging defect into the lymphatic vasculature (4). To prevent this rate limiting step of breast cancer metastasis a number of potential mechanisms of this phenomenon were investigated and described previously $(4,32,39)$. One mechanism involves 12(S)-HETE-triggered activation of $\mathrm{NF}-\mathrm{KB}$ in LECs as a significant contributor of intravasation in vitro (26-28). However, due to the versatile roles of NF- $\mathrm{KB}$ in cellular processes, including inflammatory response, tumour cell proliferation, invasion, cell survival and angiogenesis $(40,41)$, the inhibition of NF- $\kappa \mathrm{B}$ as a strategy to specifically combat metastasis has certainly its limitations. It was discovered that NF- $\mathrm{\kappa B}$ co-regulates the transcription factor SOX18 (24,25), which itself regulates PROX1 (9), which is 'the' marker for lymphatic vessels. This recommends these transcription factors as more specific targets for intervention, as they exhibit much more restricted expression profiles $(9,10)$ compared with NF- $\kappa B$.

The present data demonstrate that 12(S)-HETE induced CCID formation, which was dependent on SOX18 and its target PROX1. Additionally, the upregulation of RELA, NFKB1 and ICAM-1 were dependent on SOX18. Whether SOX18 regulated NF- $\mathrm{kB}$ expression directly or as a co-factor remains to be established.

The 12(S)-HETE-triggered signal was transduced by the high-affinity and low-affinity receptors, 12-HETER and BLT2, respectively; however, it is unknown how these receptors induced the transcription of SOX18. Notably, ectopic overexpression of SOX18 cDNA did not upregulate constitutive expression of RELA (data not shown), thus supporting a hypothetic auxiliary function of SOX18 in the regulation of $\mathrm{NF}-\kappa \mathrm{B}$, but not a direct or exclusive one. A negative auxiliary regulation of SOX18 by NF- $\kappa B$ in HUVECs was already suggested $(24,25)$, whereas the (co-) induction of NF- $\kappa B$ by SOX18 indicated a positive (auxiliary) feed-back loop between SOX18-NF-kB-SOX18 in LECs. This mechanism of regulation may be specific for LECs, as 12(S)-HETE did not induce SOX18 expression in HUVECs (data not shown).

siRNA-mediated inhibition of SOX18 and PROX1 attenuated CCID formation to a similar extent as siRNA-mediated inhibition of RELA, NFKB1 or NF- $\mathrm{KB}$ essential modulator, as demonstrated previously (28). This supports a strategy to reduce intravasation into lymphatics based on inhibition of SOX18 or PROX1 signalling (instead of NF- $\mathrm{kB}$-signalling) as it may attenuate LEC barrier intravasation with higher specificity. The expression of SOX18 and PROX1 is strongly associated with endothelial and lymph-endothelial expression and differentiation, respectively. Therefore, SOX18 mutations (causing loss of function) are associated with the rare diseases hypotrichosis-lymphedema-telangiectasia syndrome and hypotrichosis-lymphedema-telangiectasia renal defect syndrome $(42,43)$. Targeting SOX18/PROX1 would therefore, provide improved specificity in LECs. However, it will remain a matter of dispute whether inhibition of tumour 


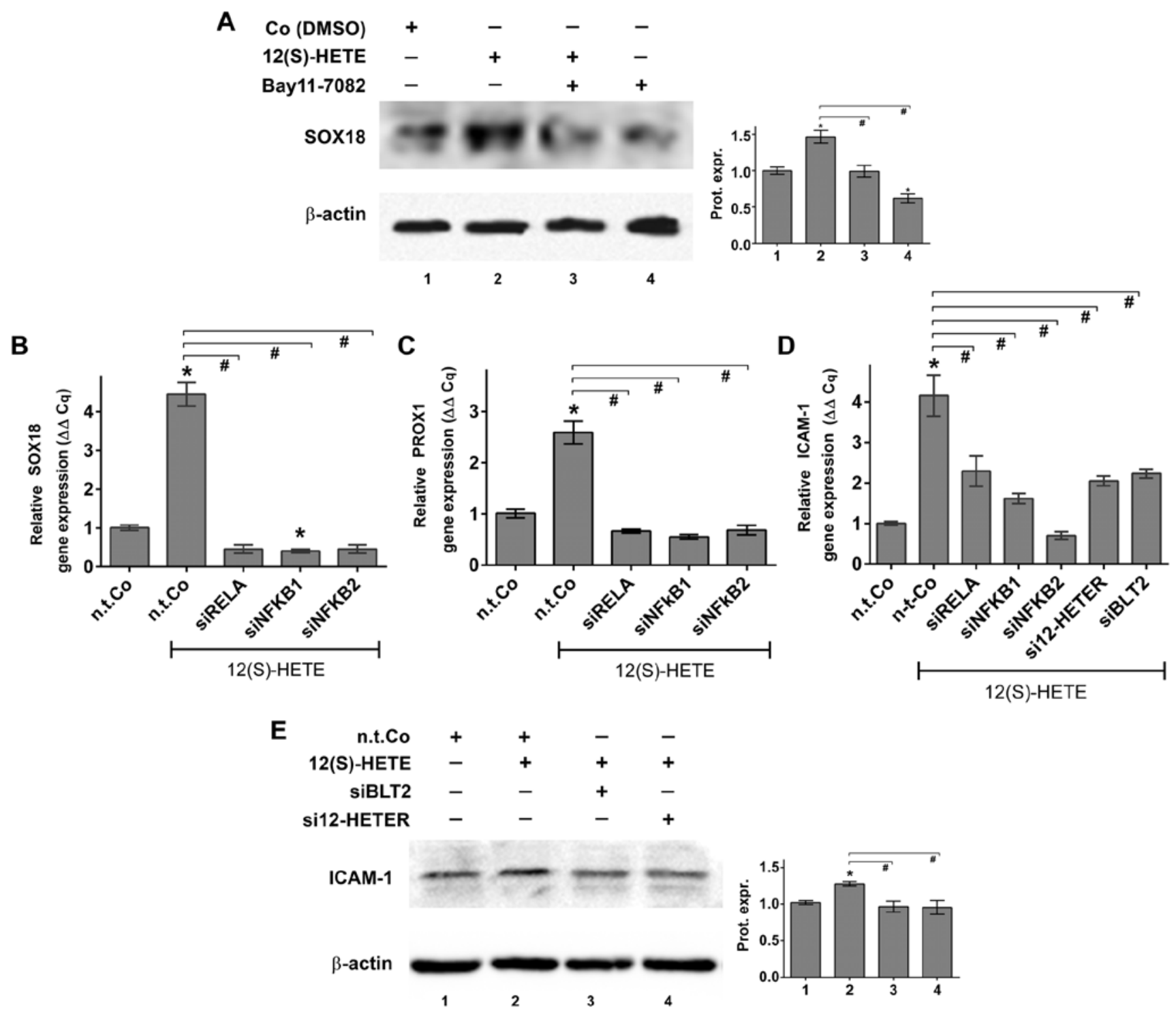

Figure 4. Suppression of NF-kB in LECs inhibits SOX18 expression. (A) Lymph endothelial cells were pre-treated with Bay11-7082 for 20 min followed by stimulation with either solvent conrol (DMSO; Co) or with $1 \mu \mathrm{M}$ 12(S)-HETE for $15 \mathrm{~min}$. Then, cells were lysed, proteins separated by SDS-PAGE and analysed by western blotting using SOX18 antibody (Ponceau S-staining and $\beta$-actin expression served as loading controls). The relative protein expression was quantified by densitometry (three replicates each). LECs were transfected either with n.t.Co or siRELA, siNFKB1 or siNFKB2 and after $24 \mathrm{~h}$ cells were stimulated with solvent (DMSO; n.t.Co) or $1.0 \mu \mathrm{M}$ 12(S)-HETE for 15 min when the mRNA expression of (B) SOX18, (C) PROX1 and (D) ICAM-1 was measured by reverse transcription-quantitative polymerase chain reaction (normalised to GAPDH mRNA; assay was performed in quadruplicate). (E) LECs were transfected with n.t.Co or siBLT2 or si12-HETER. After $24 \mathrm{~h}$ cells were stimulated with solvent (DMSO; n.t.Co) or $1 \mu \mathrm{M} 12$ (S)-HETE, lysed and analysed by SDS-PAGE and western blotting for ICAM-1 protein expression using ICAM-1 antibody (Ponceau S-staining and $\beta$-actin expression served as loading controls). Values are presented as the mean \pm standard error, ${ }^{*} \mathrm{P}<0.05$ vs. n.t.Co (no 12 (S)-HETE); ${ }^{\text {}} \mathrm{P}<0.05$ vs. n.t.Co (12(S)-HETE-treatment). LECs, lymph endothelial cells; Co, control; 12(S)-HETE, 12S-hydroxy-5Z,8Z,10E,14Z-eicosatetraenoic acid; SOX18, SRY-related HMG-box 18; n.t.Co, non-targeting control RNA; si, small interfering RNA; RELA, v-Rel avian reticuloendotheliosis viral oncogene homolog A; NFKB, nuclear factor of $\kappa$-light polypeptide gene enhancer in B cells; 12-HETER, 12(S)-HETE receptor; BLT2, leukotriene B4 receptor 2; ICAM-1, intercellular adhesion molecule 1.

intravasation has priority versus a potential induction of these rare syndromes, also involving hair loss and bleeding telangiectasia. The correct dosage may exhibit specificity in attenuating SOX18-dependent metastasis with tolerable side effects. As an example, niflumic acid, a well-known FDA-approved drug used to treat joint and muscular pain due to its cyclooxygenase-2-inhibitory properties, inhibits SOX18 at high $\mu \mathrm{M}$ concentrations (19). It was recently demonstrated that niflumic acid also inhibited NF- $\kappa B$, cytochrome P450 1A1/2 and CCID-formation at much lower concentrations (44) with a wide spectrum of activities and limited specificity for SOX18. To date, no reports regarding the identification and development of PROX1 inhibitors exist, which may target the lymphatic vasculature more precisely. Thus, future screening approaches in search of SOX18/PROX1 inhibitors are required and may reveal compounds with improved specificity. SOX18 overexpression is observed in different cancer types (12-18) causing enhanced migration, adhesion and invasivity (45). This underscores the importance to determine specific SOX18-targeting strategies (20).

SOX18 is targeted by microRNAs (miRs), miR-7a and miR-24-3p (46). Thus, miR-7a and miR-24-3p may provide another option to interfere with SOX18 activity as a therapeutic concept. Furthermore, PROX1 was also previously 

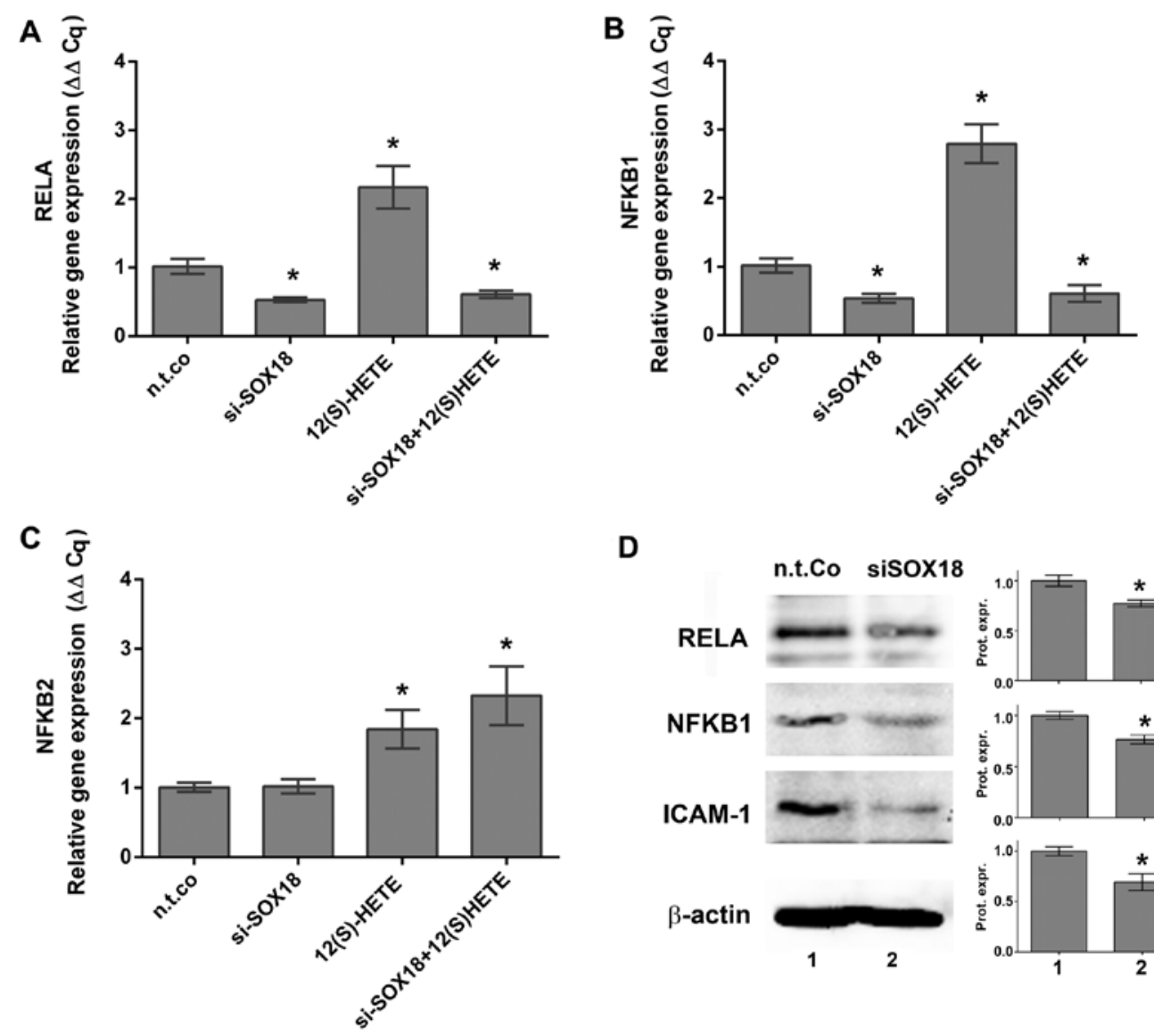

D

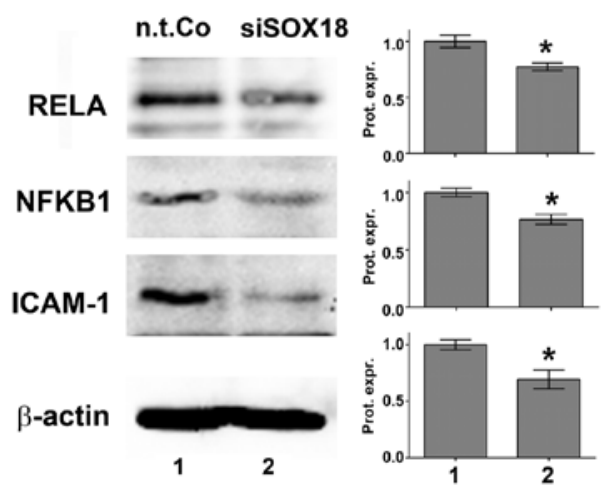

Figure 5. Suppression of SOX18 inhibits expression of RELA and NFKB1. LECs were transfected with either n.t.Co or siSOX18. After $24 \mathrm{~h}$ LECs were either treated with solvent (DMSO; n.t.Co) or $1 \mu \mathrm{M} 12$ (S)-HETE and the mRNA expression of (A) RELA, (B) NFKB1, or (C) NFKB2 was analysed by reverse transcription-quantitative polymerase chain reaction (three replicates each; normalised to GAPDH mRNA). (D) LECs were lysed, proteins separated by SDS-PAGE and expression analysed by western blotting using the indicated antibodies (Ponceau S-staining and $\beta$-actin expression served as loading controls). The relative protein expression was quantified by densitometry (three replicates each). Values are presented as the mean \pm standard error, ${ }^{*} \mathrm{P}<0.05 \mathrm{vs}$. n.t.Co. RELA, v-Rel avian reticuloendotheliosis viral oncogene homolog A; n.t.Co, non-targeting control RNA; si, small interfering RNA; SOX18, SRY-related HMG-box 18; 12(S)-HETE, 12S-hydroxy-5Z,8Z,10E,14Z-eicosatetraenoic acid; NFKB1, nuclear factor of $\kappa$-light polypeptide gene enhancer in B cells 1; ICAM-1, intercellular adhesion molecule 1.

demonstrated to be downregulated by miR-181a, thereby re-programming the lymphatic phenotype towards a blood endothelial signature (47). This phenomenon may reduce the ability of breast cancer cells to intravasate, as breast cancer cells predominantly spread through the lymphatic vasculature.

\section{Acknowledgements}

We wish to thank Mr. Toni Jäger for preparing the figures.

\section{Funding}

AF was supported by a DIKTI-OeAD fellowship and CN by a technology grant (TSA Doktorat) financed by the Austria Federal Ministry of Science and Research (BMFW) in frame of Asea Uninet. GK was supported by the Austrian Science Fund (FWF)/Herzfelder'sche Familienstiftung (project no. $\mathrm{P} 30572-\mathrm{B} 28)$.

\section{Availability of data and materials}

All data generated or analysed during this study are included in this published article. The datasets used and/or analysed during the current study are available from the corresponding author on reasonable request.

\section{Authors' contributions}

Study concepts: GK, RdM, WJ. Study design: GK, WJ, RdM, AF, DM; Data acquisition: AF, DM, CHN. Quality control of data and algorithms: GK, SK, NH, CHN, JB. Data analysis and interpretation: AF, WJ, RdM, GK. Statistical analysis: AF, DM. Manuscript preparation: GK, AF, RdM, WJ. Manuscript editing: AF, GK, RdM. All authors reviewed the manuscript.

\section{Ethics approval and consent to participate}

Not applicable.

\section{Consent for publication}

Not applicable.

\section{Competing interests}

The authors declare that they have no competing interests. 


\section{References}

1. Brabletz T, Kalluri R, Nieto MA and Weinberg RA: EMT in cancer. Nat Rev Cancer 18: 128-134, 2018.

2. van Zijl F, Krupitza G and Mikulits W: Initial steps of metastasis: Cell invasion and endothelial transmigration. Mutat Res 728: 23-34, 2011.

3. Schoppmann SF, Bayer G, Aumayr K, Taucher S, Geleff S, Rudas M, Kubista E, Hausmaninger H, Samonigg H, Gnant M, et al; Austrian Breast and Colorectal Cancer Study Group: Prognostic value of lymphangiogenesis and lymphovascular invasion in invasive breast cancer. Ann Surg 240: 306-312, 2004

4. Kerjaschki D, Bago-Horvath Z, Rudas M, Sexl V, Schneckenleithner C, Wolbank S, Bartel G, Krieger S, Kalt R, Hantusch B, et al: Lipoxygenase mediates invasion of intrametastatic lymphatic vessels and propagates lymph node metastasis of human mammary carcinoma xenografts in mouse. J Clin Invest 121: 2000-2012, 2011

5. Sobin LH, Gospodarowicz MK and Wittekind C (eds): TNM Classification of Malignant Tumours (Uicc International Union Against Cancer). 7th edition. Wiley-Blackwell, New York, NY, 2009.

6. Kanki Y, Nakaki R, Shimamura T, Matsunaga T, Yamamizu K, Katayama S, Suehiro JI, Osawa T, Aburatani H, Kodama T, et al: Dynamically and epigenetically coordinated GATA/ETS/SOX transcription factor expression is indispensable for endothelial cell differentiation. Nucleic Acids Res 45: 4344-4358, 2017.

7. Wigle JT and Oliver G: Prox1 function is required for the development of the murine lymphatic system. Cell 98: 769-778, 1999.

8. Wigle JT, Harvey N, Detmar M, Lagutina I, Grosveld G, Gunn MD, Jackson DG and Oliver G: An essential role for Prox 1 in the induction of the lymphatic endothelial cell phenotype. EMBO J 21: 1505-1513, 2002

9. François M, Caprini A, Hosking B, Orsenigo F, Wilhelm D Browne C, Paavonen K, Karnezis T, Shayan R, Downes M, et al: Sox18 induces development of the lymphatic vasculature in mice. Nature 456: 643-647, 2008 .

10. Alitalo K: The lymphatic vasculature in disease. Nat Med 17: 1371-1380, 2011.

11. Srinivasan RS, Escobedo N, Yang Y, Interiano A, Dillard ME, Finkelstein D, Mukatira S, Gil HJ, Nurmi H, Alitalo K, et al The Prox1-Vegfr3 feedback loop maintains the identity and the number of lymphatic endothelial cell progenitors. Genes Dev 28: 2175-2187, 2014.

12. Yin H, Sheng Z, Zhang X, Du Y, Qin C, Liu H, Dun Y, Wang Q, Jin C, Zhao Y, et al: Overexpression of SOX18 promotes prostate cancer progression via the regulation of TCF1, c-Myc, cyclin D1 and MMP-7. Oncol Rep 37: 1045-1051, 2017.

13. Wang Y, Guo H, Zhang D, Yu X, Leng X, Li S and Zhu W: Overexpression of SOX18 correlates with accelerated cell growth and poor prognosis in human pancreatic ductal adenocarcinoma. Biochem Biophys Res Commun 479: 510-516, 2016.

14. Ornat M, Kobierzycki C, Grzegrzolka J, Pula B, Zamirska A, Bieniek A, Szepietowski JC, Dziegiel P and Okolow MP: SOX18 Expression in Non-melanoma Skin Cancer. Anticancer Res 36 2379-2383, 2016

15. Zhang J, Ma Y, Wang S, Chen F and Gu Y: Suppression of SOX18 by siRNA inhibits cell growth and invasion of breast cancer cells. Oncol Rep 35: 3721-3727, 2016.

16. Wu Z, Liu J, Wang J and Zhang F: SOX18 knockdown suppresses the proliferation and metastasis, and induces the apoptosis of osteosarcoma cells. Mol Med Rep 13: 497-504, 2016.

17. Jia Y, Cao B, Yang Y, Linghu E, Zhan Q, Lu Y, Yu Y, Herman JG and Guo M: Silencing NKD2 by promoter region hypermethylation promotes gastric cancer invasion and metastasis by up-regulating SOX18 in human gastric cancer. Oncotarget 6: $33470-33485,2015$

18. Duong T, Proulx ST, Luciani P, Leroux JC, Detmar M, Koopman P and Francois M: Genetic ablation of SOX18 function suppresses tumor lymphangiogenesis and metastasis of melanoma in mice. Cancer Res 72: 3105-3114, 2012.

19. Fontaine F, Overman J, Moustaqil M, Mamidyala S, Salim A, Narasimhan K, Prokoph N, Robertson AAB, Lua L, Alexandrov K, et al: Small-Molecule Inhibitors of the SOX18 Transcription Factor. Cell Chem Biol 24: 346-359, 2017.

20. Overman J, Fontaine F, Moustaqil M, Mittal D, Sierecki E, Sacilotto N, Zuegg J, Robertson AA, Holmes K, Salim AA, et al: Pharmacological targeting of the transcription factor SOX18 delays breast cancer in mice. eLife 6: e21221, 2017.
21. Honn KV, Tang DG, Grossi I, Duniec ZM, Timar J, Renaud C, Leithauser M, Blair I, Johnson CR, Diglio CA, et al: Tumor cell-derived 12(S)-hydroxyeicosatetraenoic acid induces microvascular endothelial cell retraction. Cancer Res 54: 565-574, 1994.

22. Uchide K, Sakon M, Ariyoshi H, Nakamori S, Tokunaga M and Monden M: Cancer cells cause vascular endothelial cell (vEC) retraction via 12(S)HETE secretion; the possible role of cancer cell derived microparticle. Ann Surg Oncol 14: 862-868, 2007.

23. Rigby DA, Ferguson DJ, Johnson LA and Jackson DG: Neutrophils rapidly transit inflamed lymphatic vessel endothelium via integrindependent proteolysis and lipoxin-induced junctional retraction. J Leukoc Biol 98: 897-912, 2015.

24. Basílio J, Hoeth M, Holper-Schichl YM, Resch U, Mayer H, Hofer-Warbinek R and de Martin R: TNFa-induced downregulation of Sox18 in endothelial cells is dependent on NF- $\mathrm{KB}$. Biochem Biophys Res Commun 442: 221-226, 2013.

25. Gross CM, Kellner M, Wang T, Lu Q, Sun X, Zemskov EA, Noonepalle S, Kangath A, Kumar S, Gonzalez-Garay M, et al: LPS Induced Acute Lung Injury Involves the NF- $\mathrm{BB}$-mediated Downregulation of SOX18. Am J Respir Cell Mol Biol: Nov 8, 2017 (Epub ahead of print). doi: 10.1165/rcmb.2016-0390OC

26. Vonach C, Viola K, Giessrigl B, Huttary N, Raab I, Kalt R, Krieger S, Vo TP, Madlener S, Bauer S, et al: NF- $\kappa \mathrm{B}$ mediates the 12(S)-HETE-induced endothelial to mesenchymal transition of lymphendothelial cells during the intravasation of breast carcinoma cells. Br J Cancer 105: 263-271, 2011.

27. Viola K, Kopf S, Huttary N, Vonach C, Kretschy N, Teichmann M, Giessrigl B, Raab I, Stary S, Krieger S, et al: Bay11-7082 inhibits the disintegration of the lymphendothelial barrier triggered by MCF-7 breast cancer spheroids; the role of ICAM-1 and adhesion. Br J Cancer 108: 564-569, 2013.

28. Nguyen CH, Senfter D, Basilio J, Holzner S, Stadler S, Krieger S, Huttary N, Milovanovic D, Viola K, Simonitsch-Klupp I, et al: $\mathrm{NF}-\kappa \mathrm{B}$ contributes to MMP1 expression in breast cancer spheroids causing paracrine PAR 1 activation and disintegrations in the lymph endothelial barrier in vitro. Oncotarget 6: 39262-39275, 2015.

29. Schoppmann SF, Soleiman A, Kalt R, Okubo Y, Benisch C, Nagavarapu U,Herron GS and Geleff S: Telomerase-immortalized lymphatic and blood vessel endothelial cells are functionally stable and retain their lineage specificity. Microcirculation 11: 261-269, 2004

30. Yang J, Chang E, Cherry AM, Bangs CD, Oei Y, Bodnar A, Bronstein A, Chiu CP and Herron GS: Human endothelial cell life extension by telomerase expression. J Biol Chem 274: 26141-26148, 1999.

31. Livak KJ and Schmittgen TD: Analysis of relative gene expression data using real-time quantitative PCR and the 2(-Delta Delta C(T)) method. Methods 25: 402-408, 2001

32. Nguyen CH, Stadler S, Brenner S, Huttary N, Krieger S, Jäger W, Dolznig H and Krupitza G: Cancer cell-derived 12(S)-HETE signals via 12-HETE receptor, RHO, ROCK and MLC2 to induce lymph endothelial barrier breaching. Br J Cancer 115: 364-370, 2016.

33. Nguyen $\mathrm{CH}$, Brenner S, Huttary N, Atanasov AG, Dirsch VM, Chatuphonprasert W, Holzner S, Stadler S, Riha J, Krieger S, et al: AHR/CYP1A1 interplay triggers lymphatic barrier breaching in breast cancer spheroids by inducing 12(S)-HETE synthesis. Hum Mol Genet 25: 5006-5016, 2016b.

34. Klaus M, Prokoph N, Girbig M, Wang X, Huang YH, Srivastava Y, Hou L, Narasimhan K, Kolatkar PR, Francois M, et al: Structure and decoy-mediated inhibition of the SOX18/Prox1-DNA interaction. Nucleic Acids Res 44: 3922-3935, 2016.

35. Brown JD, Lin CY, Duan Q, Griffin G, Federation A, Paranal RM, Bair S, Newton G, Lichtman A, Kung A, et al: NF- $\mathrm{BB}$ directs dynamic super enhancer formation in inflammation and atherogenesis. Mol Cell 56: 219-231, 2014.

36. Van den Eynden GG, Vandenberghe MK, van Dam PJ, Colpaert CG, van Dam P, Dirix LY, Vermeulen PB and Van Marck EA: Increased sentinel lymph node lymphangiogenesis is associated with nonsentinel axillary lymph node involvement in breast cancer patients with a positive sentinel node. Clin Cancer Res 13: 5391-5397, 2007.

37. Chen Y, Yan J, Yuan Z, Yu S, Yang C, Wang Z and Zheng Q: A meta-analysis of the relationship between lymphatic microvessel density and clinicopathological parameters in breast cancer. Bull Cancer 100: 1-10, 2013.

38. Zhang S, Zhang D, Gong M, Wen L, Liao C and Zou L: High lymphatic vessel density and presence of lymphovascular invasion both predict poor prognosis in breast cancer. BMC Cancer 17: 335,2017 
39. Nguyen CH, Brenner S, Huttary N,Li Y, Atanasov AG, Dirsch VM, Holzner S, Stadler S, Riha J, Krieger S, et al: 12(S)-HETE increases intracellular $\mathrm{Ca}(2+)$ in lymph-endothelial cells disrupting their barrier function in vitro; stabilization by clinical drugs impairing calcium supply. Cancer Lett 380: 174-183, 2016c.

40. Brown M, Cohen J, Arun P, Chen Z and Van Waes C: NF-kappaB in carcinoma therapy and prevention. Expert Opin Ther Targets 12: 1109-1122, 2008.

41. Flister MJ, Wilber A, Hall KL, Iwata C, Miyazono K, Nisato RE, Pepper MS, Zawieja DC and Ran S: Inflammation induces lymphangiogenesis through up-regulation of VEGFR-3 mediated by NF-kappaB and Prox1. Blood 115: 418-429, 2010.

42. Irrthum A, Devriendt K, Chitayat D, Matthijs G, Glade C, Steijlen PM, Fryns JP, Van Steensel MA and Vikkula M: Mutations in the transcription factor gene SOX18 underlie recessive and dominant forms of hypotrichosis-lymphedematelangiectasia. Am J Hum Genet 72: 1470-1478, 2003.

43. Moalem S, Brouillard P, Kuypers D, Legius E, Harvey E, Taylor G, Francois M,Vikkula M and ChitayatD: Hypotrichosis-lymphedematelangiectasia-renal defect associated with a truncating mutation in the SOX18 gene. Clin Genet 87: 378-382, 2015.
44. Nguyen $\mathrm{CH}$, Huttary N, Atanasov AG, Chatuphonprasert W, Brenner S, Fristiohady A, Hong J, Stadler S, Holzner S, Milovanovic D, et al: Fenofibrate inhibits tumour intravasation by several independent mechanisms in a 3-dimensional co-culture model. Int J Oncol 50: 1879-1888, 2017.

45. Wang G, Wei Z, Jia H, Zhao W, Yang G and Zhao H: Knockdown of SOX18 inhibits the proliferation, migration and invasion of hepatocellular carcinoma cells. Oncol Rep 34: 1121-1128, 2015.

46. Olbromski M,Grzegrzolka J,Jankowska-Konsur A, Witkiewicz W, Podhorska-Okolow M and Dziegiel P: MicroRNAs modulate the expression of the SOX18 transcript in lung squamous cell carcinoma. Oncol Rep 36: 2884-2892, 2016.

47. Kazenwadel J, Michael MZ and Harvey NL: Prox1 expression is negatively regulated by miR-181 in endothelial cells. Blood 116: 2395-2401, 2010. 